\title{
Thoracic skeletal muscle quantification: low muscle mass is related with worse prognosis in idiopathic pulmonary fibrosis patients
}

Sung Woo Moon, Ji Soo Choi, Sang Hoon Lee, Kyung Soo Jung, Ji Ye Jung, Young Ae Kang, Moo Suk Park, Young Sam Kim, Joon Chang and Song Yee Kim ${ }^{*}$

\begin{abstract}
Background: Sarcopenia can contribute to negative outcomes in patients with various lung diseases. However, whether sarcopenia affects prognosis in patients with idiopathic pulmonary fibrosis (IPF) has not been reported. Simple measures of muscle mass, derived from chest computed tomography (CT), are increasingly being used to identify patients with sarcopenia. We hypothesized that skeletal muscle mass could be a predictor of prognosis in IPF patients.

Methods: We retrospectively evaluated 180 patients diagnosed with IPF between January 2010 and December 2015 at a tertiary care hospital in South Korea. We measured thoracic muscle volume by using the cross-sectional area (CSA) of the pectoralis, paraspinal, serratus, and latissimus muscles at the 4th vertebral region ( $T_{\text {CSA }}$ ) and the erector spinae muscle (ESM $\left.M_{C S A}\right)$ at the 12th vertebral region. CT scans at the time of diagnosis were used for analysis and respective CSA were divided by height squared to normalize for stature. Survival times were estimated with the Kaplan-Meier method and compared with the log-rank test. Multivariate Cox proportional hazards models were performed to investigate relationships between clinical parameters and mortality.

Results: Male patients in the lowest quartile of $\mathrm{T}_{\mathrm{CSA}}$ divided by height squared $\left(\mathrm{m}^{2}\right)(\mathrm{T} 4 \mathrm{MI})$ and in the lowest quartile

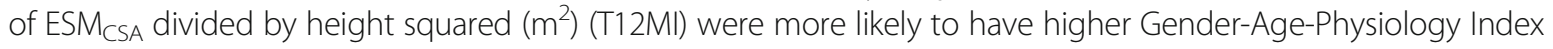
scores (T4MI, $3.3 \pm 1.3$ vs $4.0 \pm 1.6, P=0.012 ; \mathrm{T} 12 \mathrm{Ml}, 3.2 \pm 1.3$ vs $4.1 \pm 1.6, P=0.002$ ). Male patients in the lowest quartile of T4Ml exhibited a significantly lower survival rate $(P=0.035)$. After multivariate Cox proportional hazards analysis, T4MI was a significant risk factor for all-cause mortality $(\mathrm{HR}, 0.955 ; 95 \% \mathrm{Cl}, 0.913-0.998 ; P=0.041)$, whereas T12MI was not ( $\mathrm{HR}, 0.980 ; 95 \% \mathrm{Cl}, 0.856-1.121 ; P=0.766)$.
\end{abstract}

Conclusions: Low skeletal mass normalized for stature at the level of 4th vertebrae which can be acquired by quantifying thoracic skeletal muscle on single-slice axial chest $C T$, may be a strong risk factor for all-cause mortality in patients with IPF.

Trial registration: The research protocol was approved by the Institutional Review Board of Severance Hospital, South Korea (IRB No.4-2018-0454).

Keywords: Idiopathic pulmonary fibrosis, Sarcopenia, Computed tomography, Skeletal muscle, Mortality

\footnotetext{
*Correspondence: dobie@yuhs.ac

Division of Pulmonary Medicine Department of Internal Medicine, Yonsei

University College of Medicine, 50 Yonsei-ro, Seodaemun-gu, Seoul 120-752,

Republic of Korea
}

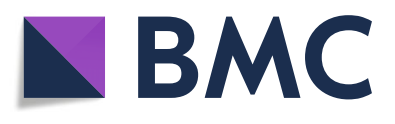

(c) The Author(s). 2019 Open Access This article is distributed under the terms of the Creative Commons Attribution 4.0 International License (http://creativecommons.org/licenses/by/4.0/), which permits unrestricted use, distribution, and reproduction in any medium, provided you give appropriate credit to the original author(s) and the source, provide a link to the Creative Commons license, and indicate if changes were made. The Creative Commons Public Domain Dedication waiver (http://creativecommons.org/publicdomain/zero/1.0/) applies to the data made available in this article, unless otherwise stated. 


\section{Introduction}

Sarcopenia is the progressive loss of muscle mass and strength, which is associated with a risk of adverse outcomes, such as disability, poor quality of life, and death [1]. Sarcopenia can cause negative outcomes in patients with various lung diseases, as well as non-lung diseases, such as cholangiocarcinoma and breast cancer [2-7]. Idiopathic pulmonary fibrosis (IPF) is a specific form of chronic, progressive, fibrosing interstitial pneumonia of unknown cause; it occurs primarily in adults and is limited to the lungs [8]. Indexes of IPF prognosis include symptoms, respiratory function, and imaging, which are important to consider in the clinical progression of IPF [8]. However, the effect of sarcopenia on prognosis in patients with IPF has not been reported.

Several modalities have been used to assess sarcopenia. Bioelectrical impedance analysis, dual energy $\mathrm{X}$-ray absorptiometry, magnetic resonance imaging, and B-mode ultrasound are widely used to quantify both total and local skeletal muscle mass [1]. Measurement of the cross-sectional area (CSA) of skeletal muscles on single-slice axial computed tomography (CT) scans is an alternative method to assess local skeletal muscle mass [9]. Simple measures of muscle mass, derived from $\mathrm{CT}$ of the abdominal region, are increasingly used to identify patients with sarcopenia $[3,6$, $10,11]$. A limitation of this method for evaluating muscle CSA in chronic respiratory disease is that abdominal CT scans are not typically performed in clinical respiratory assessment. However, correlations have been found between muscle CSA at a single thoracic level on chest CT and total muscle volume in patients with advanced lung disease [12-14].

Rozenberg et al. observed that, at the level of carina, which corresponds to the 4th vertebral region, the CSA of the pectoralis, intercostalis, paraspinals, serratus, and latissimus muscles was associated with frailty markers, such as 6-min walk distance, biceps training volume, quadriceps training volume, and length of hospital stay in lung transplant patients [15]. Zuckerman et al. reported similar observations regarding the CSA at the 4th vertebral region, which was associated with frailty markers [7]. Fuseya et al. observed that, at the lower margin of the 12th vertebral region, CSA of erector spinae muscle $\left(\mathrm{ESM}_{\mathrm{CSA}}\right)$, a major antigravity muscle group, was associated with severe airflow limitation, respiratory symptoms, emphysema severity, and mortality in chronic obstructive lung disease patients [12].

In this study, we focused on pectoralis, paraspinals, serratus, and latissimus muscles at the 4th vertebral region and erector spinae muscle at the 12 th vertebral region. We hypothesized that skeletal muscle mass, measured by analyzing muscle CSA from chest CT images at the 4th and 12th vertebral regions, could be a predictor of prognosis in IPF patients.

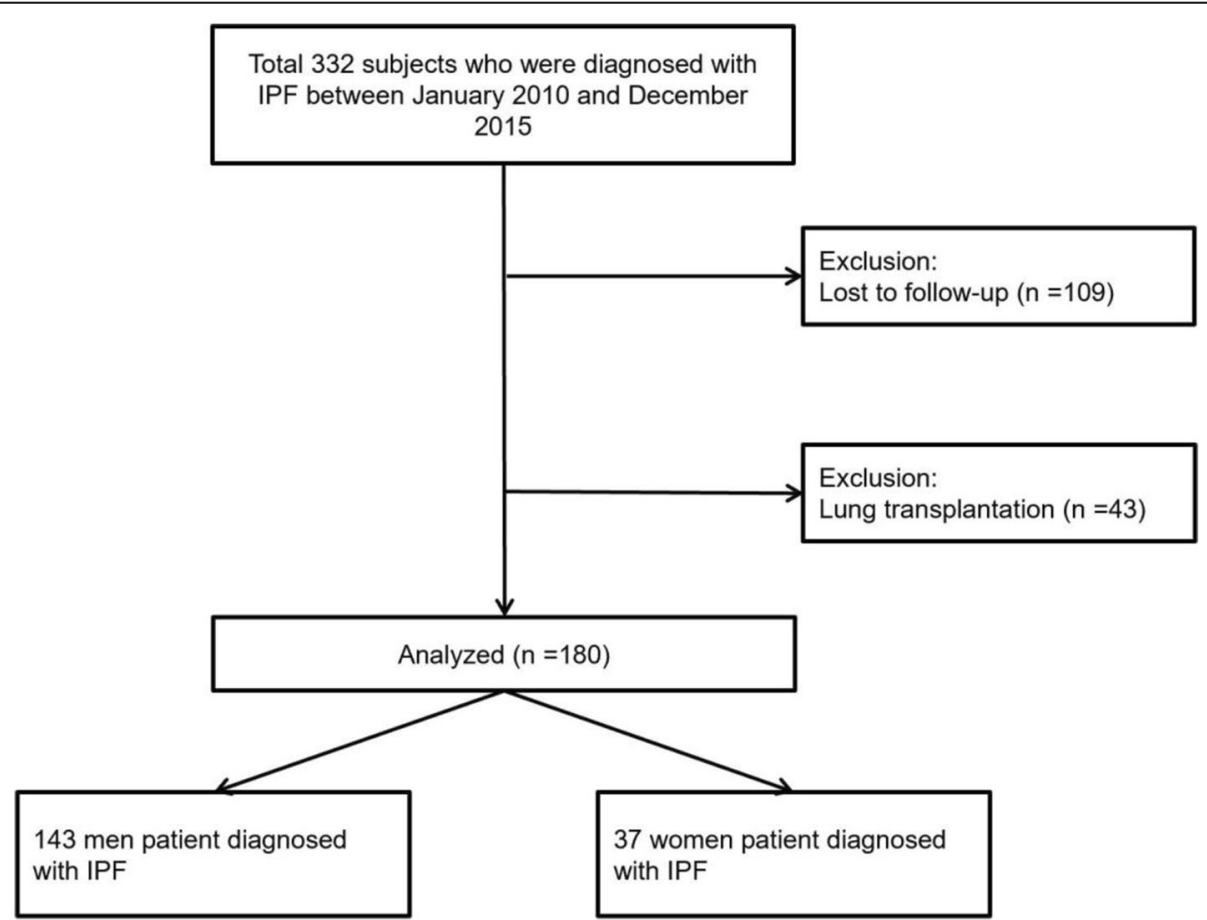

Fig. 1 Flow diagram of subjects in this study. Abbreviations; IPF, Idiopathic pulmonary fibrosis; ILD, Interstitial lung disease 


\section{Materials and methods}

\section{General methods}

We retrospectively reviewed medical records of patients who were diagnosed with IPF between January 2010 and December 2015 at one tertiary care hospital in South Korea. IPF was diagnosed according to an official ATS/ ERS/JRS/ALAT statement [16]. Diagnosis was confirmed by a multi-disciplinary team consisting of specialists in pulmonary medicine, radiology, and pathology.

The flow diagram depicting the selection process of subjects in this study is shown in Fig. 1. Initially, 332 patients who were diagnosed with IPF were included in the study, selected from our institutional database based on the following criteria: (1) Patients with confirmed IPF by either clinical findings or biopsy; (2) CT scan images at the time of diagnosis were saved in our institutional radiology database; (3) clinical data were available from the medical records. Subsequently, patients who underwent lung transplantation $(n=43)$, and patients who were lost to follow-up $(n=109)$ were excluded. Finally, 180 subjects (143 men and 37 women) were included in the analysis.

Age, smoking history, pulmonary function test results, underlying diseases including diabetes, height, weight at the time of the diagnosis, Gender-Age-Physiology (GAP) Index [17], usage of drugs that may affect skeletal muscle mass [18] (statins, sulfonylureas, glinides) and mortality data were collected for all patients; data regarding thoracic muscle cross-sectional area (CSA) at the level of the 4th thoracic vertebra were available in all patients; data regarding erector spinae muscle CSA at the level of the 12th thoracic vertebra were available in 174 patients. Computed tomography scan images at the time of diagnosis were used for analysis. Follow-up data, including mortality data, were collected until December 2017.

The exact definition of and standardized measurement techniques for sarcopenia have not yet been established at the level of T4 or T12 in IPF patients. Therefore, additional predictor variables were determined based on studies performed by Rozenberg et al. [15] and Fuseya et al. [12] We measured sarcopenia indirectly with thoracic muscle (e.g. pectoralis, intercostalis, paraspinals, serratus, latissimus muscles) CSA, measured at $\mathrm{T} 4\left(\mathrm{~T}_{\mathrm{CSA}}\right)$. We divided the cross-sectional area of skeletal muscle $\left(\mathrm{cm}^{2}\right)$ at the T4 level by height squared $\left(\mathrm{m}^{2}\right)$ to yield the muscle index at T4 (T4MI, $\mathrm{cm}^{2} / \mathrm{m}^{2}$ ), normalized for stature. We also sought to measure sarcopenia indirectly with the CSA of the ESM at the T12 level. We divided the CSA of ESM $\left(\mathrm{ESM}_{\mathrm{CSA}}, \mathrm{cm}^{2}\right)$ at the T12 level by height squared $\left(\mathrm{m}^{2}\right)$ to yield the muscle index at T12 (T12MI, $\mathrm{cm}^{2} / \mathrm{m}^{2}$ ), normalized for stature. The primary outcomes were overall survival, 1-year survival, and 2-year survival after diagnosis. Overall survival was estimated from the date of baseline CT to death or the last follow-up.
Measurement of skeletal muscle CSA at the level of T4, T12 Chest CT examinations were obtained by 16-detector CT scanners (Somatom Emotion 16; Siemens Healthcare, Erlangen, Germany). Non-contrast CTs were used in the analysis. Quantitative assessment of the CSA was performed semi-automatically with Aquarius iNtuition Viewer (ver. 4.4.11, TeraRecon Inc., San Mateo, CA, USA) as shown in Fig. 2. T4 was defined as the slice including the middle of 4th thoracic vertebrae, and T12 was defined as the slice including the middle of 12th thoracic vertebrae; the observer visually identified single cross-sectional images at the levels of $\mathrm{T} 4$ and $\mathrm{T} 12$,


Fig. 2 a, b: Sample computed tomography (CT) scans used to determine muscle area in idiopathic pulmonary fibrosis case subjects. Chest CT examinations were obtained by using 24-detector CT scanners (Somatom Emotion 16; Siemens Healthcare, Erlangen, Germany). Non-contrast CTs were used in the analysis. Quantitative assessment of the CSA was performed semi-automatically with Aquarius iNtuition Viewer (ver. 4.4.11, TeraRecon Inc., San Mateo, CA, USA) (a) Axial CT image of the 4th thoracic vertebral region. Pectoralis, intercostalis, paraspinals, serratus, and latissimus muscles are in blue. $\mathbf{b}$ Axial CT image of the 12th thoracic vertebral region. Erector spinae muscles are in blue 
respectively. At the T4 level, we then outlined the borders of the thoracic and back muscles. At the T12 level, we outlined the borders of the ESM. Tissue CSAs in slices were computed automatically by summation of the pixel attenuation of -30 to +150 Hounsfield units for skeletal muscle. After applying the threshold method (with a predefined Hounsfield unit threshold) to slices, boundaries between different tissues were corrected manually when necessary. After measuring CSAs, respective CSA was divided by height square to normalize for stature, as used in previous studies. A radiology technician performed measurement of the CSA without access to patient information.

\section{Statistical methods}

Descriptive statistics are reported as numbers with proportions or means with standard deviations (SDs). The continuous variables were tested for normality by using the Kolmogorov-Smirnov test. Chi-squared tests or Fisher's exact tests were conducted to compare categorical variables between the male and female groups, sarcopenia and normal groups; Student's t-tests or Mann-Whitney tests were conducted to compare continuous variables between the two groups. Survival times were estimated with the Kaplan-Meier method and compared with the log-rank test. Multivariate Cox proportional hazards models were performed to investigate relationships between clinical parameters and mortality. Variables with a $P$-value of $<0.15$ by the log-rank test were included; variables that overlap (e.g., age, gender, forced vital capacity (FVC), and diffusing capacity of carbon monoxide $\left(\mathrm{DL}_{\mathrm{CO}}\right)$ in GAP index) were excluded. An adjusted $P$-value $<0.05$ was considered statistically significant. All statistical analyses were performed with SPSS version 20.0 (SPSS Inc., Chicago, IL, USA).

Table 1 Patient characteristics

\begin{tabular}{|c|c|c|c|c|}
\hline Variable & Total & Men & Women & P-value \\
\hline Number of patients, $\mathrm{n}$ & 180 & $143(79.4 \%)$ & $37(20.6 \%)$ & \\
\hline Age, years & $69.1(44-94)$ & $68.7(44-89)$ & $70.0(52-94)$ & 0.214 \\
\hline Height, meters, $\mathrm{m}$ & $1.6 \pm 0.1(1.4-1.8)$ & $1.7 \pm 0.1(1.5-1.8)$ & $1.5 \pm 0.1(1.4-1.7)$ & $<0.001$ \\
\hline Weight, kg & $63.9 \pm 10.3(33.1-97.3)$ & $65.7 \pm 10.2(33.1-97.3)$ & $56.9 \pm 7.1(46.0-73.0)$ & $<0.001$ \\
\hline $\mathrm{BMl}, \mathrm{kg} / \mathrm{m}^{2}$ & $23.9 \pm 3.2(12.2-34.9)$ & $23.8 \pm 3.3(12.2-34.9)$ & $24.0 \pm 3.2(17.6-29.6)$ & 0.794 \\
\hline Ever smoker, \% & $129(71.6 \%)$ & $126(88.1 \%)$ & $3(8.1 \%)$ & $<0.001$ \\
\hline Smoking history, pack-years & $31.0 \pm 23.3(0-150)$ & $31.5 \pm 23.3(0-150)$ & $8.3 \pm 7.6(0-15)$ & 0.088 \\
\hline Diabetes, n & $59(32.8 \%)$ & $47(32.9 \%)$ & $12(32.4 \%)$ & 1.000 \\
\hline Use of Statins or Sulfonylureas or Glinides, n & $66(36.7 \%)$ & $52(37.1 \%)$ & $13(35.1 \%)$ & 1.000 \\
\hline FVC, L & $2.6 \pm 0.8(0.9-4.8)$ & $2.8 \pm 0.8(0.9-4.8)$ & $1.8 \pm 0.5(0.9-2.8)$ & $<0.001$ \\
\hline FVC, \% predicted & $76.3 \pm 17.1(31-110)$ & $77.1 \pm 17.1(31-110)$ & $72.8 \pm 16.6(34-106)$ & 0.185 \\
\hline $\mathrm{FEV}_{1}, \mathrm{~L}$ & $2.1 \pm 0.6(0.8-3.9)$ & $2.2 \pm 0.6(0.8-3.9)$ & $1.3 \pm 0.4(0.8-2.3)$ & $<0.001$ \\
\hline $\mathrm{FEV}_{1}, \%$ predicted & $89.0 \pm 18.6(34-128)$ & $89.3 \pm 18.9(34-128)$ & $88.2 \pm 17.7(45-119)$ & 0.753 \\
\hline $\mathrm{FEV}_{1} / \mathrm{FVC}, \%$ & $81.44 \pm 8.97(31-100)$ & $80.53 \pm 9.07(31-100)$ & $85.15 \pm 7.60(70-98)$ & 0.007 \\
\hline TLC, L & $4.73 \pm 1.42(1.91-8.40)$ & $5.03 \pm 1.31(2.55-8.40)$ & $3.10 \pm 0.70(1.91-4.70)$ & $<0.001$ \\
\hline $\mathrm{DL}_{\mathrm{CO}}, \mathrm{ml} / \mathrm{min} / \mathrm{mm} \mathrm{Hg}$ & $12.2 \pm 5.2(2.9-46.5)$ & $12.8 \pm 5.3(2.9-46.5)$ & $9.9 \pm 3.7(4.2-17.3)$ & 0.005 \\
\hline $\mathrm{DL}_{\mathrm{CO}}, \%$ predicted & $69.6 \pm 23.1(20-149)$ & $71.6 \pm 23.3(20-149)$ & $61.1 \pm 20.6(25-102)$ & 0.025 \\
\hline T4 level muscle CSA, $\mathrm{cm}^{2}$ & $96.0 \pm 25.6(36.8-163.5)$ & $102.4 \pm 23.4(36.8-163.5)$ & $71.4 \pm 18.1(33.4-111.3)$ & $<0.001$ \\
\hline${ }^{\mathrm{T} T 4}$ level muscle index, $\mathrm{cm}^{2} / \mathrm{m}^{2}$ & $35.7 \pm 8.5(13.2-55.9)$ & $37.2 \pm 8.2(13.2-55.9)$ & $30.0 \pm 7.5(17.9-45.0)$ & $<0.001$ \\
\hline T12 Erector spinae muscle CSA, $\mathrm{cm}^{2}$ & $28.2 \pm 9.1(9.8-55.9)$ & $29.4 \pm 8.2(13.2-55.9)$ & $23.5 \pm 7.5(9.8-38.8)$ & 0.001 \\
\hline${ }^{\mathrm{b}} \mathrm{T} 12$ muscle index, $\mathrm{cm}^{2} / \mathrm{m}^{2}$ & $10.5 \pm 3.3(3.8-23.2)$ & $10.7 \pm 3.3(3.8-23.2)$ & $9.9 \pm 3.1(4.5-15.8)$ & 0.184 \\
\hline Follow-up time, months & $37.9 \pm 22.5(0.1-91)$ & $37.0 \pm 21.9(0.1-90.8)$ & $41.3 \pm 25.0(0.4-91)$ & 0.301 \\
\hline GAP Index score & $3.3 \pm 1.4(0-7)$ & $3.5 \pm 1.4(1-7)$ & $2.8 \pm 1.5(0-6)$ & 0.006 \\
\hline 1-year survival, number, (\%) & $157(87.2 \%)$ & $124(86.7 \%)$ & $33(89.2 \%)$ & 0.688 \\
\hline 2-year survival, number, (\%) & $138(76.7 \%)$ & $107(74.8 \%)$ & $31(83.8 \%)$ & 0.284 \\
\hline
\end{tabular}

Continuous variables are presented as mean \pm standard deviation (range) and categorical variables are presented as numbers (percentage) Abbreviations: BMI Body Mass Index, FEV1 Forced Expiratory Volume, FVC Forced Vital Capacity, TLC Total Lung Capacity, DL $C O$ diffusing capacity of carbon monoxide, CSA Cross Sectional Area, GAP gender, age, and physiologic variables

${ }^{a}$ T4 level muscle index $=$ CSA of pectoralis, intercostalis, paraspinals, serratus, and latissimus muscles at T4 level/height ${ }^{2}$

${ }^{\mathrm{b}} \mathrm{T} 12$ level muscle index $=$ CSA of erector spinae muscle at $\mathrm{T} 12$ level/height ${ }^{2}$ 


\section{Results}

\section{Baseline characteristics}

Baseline characteristics of the study subjects are provided in Table 1. The proportion of male patients was $79.4 \%$. The mean age for all patients was 69.1 years (range, 44-94 years); the mean ages of male and female patients were 68.7 years (range, 44-89 years) and 70.0 years (range, 52-94 years), respectively.

Compared with female patients, male patients had higher body mass indexes (BMI), a greater tendency to be smokers, higher FVC, L, forced expiratory volume $\left(\mathrm{FEV}_{1}\right)$, L, and $\mathrm{FEV}_{1} / \mathrm{FVC}, \mathrm{DL}_{\mathrm{CO}}$, higher GAP index score, higher T4 $4_{C S A}$ and ESM ${ }_{C S A}$, higher T4MI $\left(37.2 \mathrm{~cm}^{2} / \mathrm{m}^{2}\right.$ vs. $30.0 \mathrm{~cm}^{2} / \mathrm{m}^{2}$, respectively, $\left.P<0.001\right)$. FVC and $\mathrm{FEV}_{1}$ percentage of predicted value, and T12MI did not differ significantly between male and female patients.

Of 143 male patients with IPF, 53 (37.1\%) died during the follow-up period. Respective 1-year survival and 2 -year survival rates were 86.7 and $74.8 \%$. Of 37 female patients with IPF, 15 (40.5\%) died during the follow-up period. Respective 1-year survival and 2-year survival rates were 89.2 and $83.8 \%$. One-year $(P=0.688)$ and two-year survival $(P=0.284)$ rates did not differ between male and female patients.

\section{Clinical characteristics and survival}

We divided the patients into two groups according to CSA divided by height square to visualize the effects of lowest quartile CSA divided by height square. Male and female patients were divided and analyzed separately as male and female exhibited significant difference in muscle mass. And there is no defined cutoff point for defining sarcopenia in chest CT in T4 and T12 levels, we divided the patients into four groups according to T4MI and T12MI in male and female, respectively. And lowest quartile of T4MI or T12MI groups was defined as sarcopenia group.

When patients were stratified by $\mathrm{T}_{\mathrm{CSA}}$ divided by height square (T4MI) $(n=143)$; comparisons of clinical characteristics and survival between the lowest quartile of T4MI (sarcopenia) (Q4) and the rest (normal) group $(\mathrm{Q} 1+2+3)$ are shown in Table 2. The cutoff value

Table 2 Comparisons between Sarcopenia (lowest quartile of T4MI) (Q4) and the normal group (Q1 + Q2 + Q3) among men and women, respectively

\begin{tabular}{|c|c|c|c|c|c|c|}
\hline \multirow[t]{2}{*}{ Variable } & \multicolumn{3}{|l|}{$\operatorname{Men}(n=143)$} & \multicolumn{3}{|l|}{ Women $(n=37)$} \\
\hline & Normal $(n=107)$ & Sarcopenia $(n=36)$ & $P$-value & Normal $(n=28)$ & Sarcopenia $(n=9)$ & P-value \\
\hline Age, years & $68.1 \pm 7.9$ & $70.8 \pm 8.9$ & 0.087 & $70.4 \pm 8.2$ & $71.6 \pm 13.2$ & 0.808 \\
\hline $\mathrm{BMI}, \mathrm{kg} / \mathrm{m}^{2}$ & $24.0 \pm 3.1$ & $23.3 \pm 3.7$ & 0.283 & $24.4 \pm 3.1$ & $22.7 \pm 3.5$ & 0.231 \\
\hline Ever smoker, \% & $92(88.8 \%)$ & $31(86.1 \%)$ & 0.336 & $3(10.7 \%)$ & $0(0.0 \%)$ & 0.592 \\
\hline Smoking history, pack-years & $32.1 \pm 23.9$ & $29.7 \pm 21.5$ & 0.594 & $8.3 \pm 7.6$ & 0 & $\mathrm{n} / \mathrm{a}$ \\
\hline Diabetes, n & $36(33.6 \%)$ & $11(30.6 \%)$ & 0.839 & $8(28.6 \%)$ & $4(44.4 \%)$ & 0.432 \\
\hline Use of Statins or Sulfonylureas or Glinides, $n$ & $42(39.3 \%)$ & $11(30.6 \%)$ & 0.427 & $7(25 \%)$ & $6(66.7 \%)$ & 0.042 \\
\hline FVC, L & $2.9 \pm 0.7$ & $2.62 \pm 0.84$ & 0.096 & $1.8 \pm 0.5$ & $1.7 \pm 0.6$ & 0.888 \\
\hline FVC, \% predicted & $78.9 \pm 16.2$ & $72.0 \pm 18.9$ & 0.040 & $73.8 \pm 16.3$ & $68.7 \pm 18.1$ & 0.516 \\
\hline $\mathrm{FEV}_{1}, \mathrm{~L}$ & $2.3 \pm 0.6$ & $2.14 \pm 0.63$ & 0.241 & $1.5 \pm 0.4$ & $1.5 \pm 0.5$ & 0.982 \\
\hline $\mathrm{FEV}_{1}, \%$ predicted & $90.4 \pm 18.0$ & $86.1 \pm 21.2$ & 0.249 & $88.9 \pm 17.8$ & $85.3 \pm 18.4$ & 0.649 \\
\hline $\mathrm{FEV}_{1} / \mathrm{FVC}_{1} \%$ & $79.8 \pm 9.3$ & $82.6 \pm 8.1$ & 0.117 & $84.6 \pm 7.8$ & $87.1 \pm 6.6$ & 0.409 \\
\hline$D L_{c o}, \%$ predicted & $73.7 \pm 22.8$ & $64.9 \pm 23.9$ & 0.065 & $59.8 \pm 20.3$ & $66.2 \pm 22.6$ & 0.551 \\
\hline T4 level muscle CSA, $\mathrm{cm}^{2}$ & $111.7 \pm 17.4$ & $74.7 \pm 15.6$ & $<0.001$ & $78.2 \pm 14.8$ & $50.3 \pm 8.3$ & $<0.001$ \\
\hline${ }^{\mathrm{a}} \mathrm{T} 4$ level muscle index, $\mathrm{cm}^{2} / \mathrm{m}^{2}$ & $40.6 \pm 5.8$ & $26.86 \pm 5.01$ & $<0.001$ & $33.0 \pm 6.0$ & $20.8 \pm 2.0$ & $<0.001$ \\
\hline T12 Erector spinae muscle CSA, $\mathrm{cm}^{2}$ & $31.8 \pm 8.4$ & $21.99 \pm 7.46$ & $<0.001$ & $26.0 \pm 5.6$ & $15.2 \pm 5.8$ & $<0.001$ \\
\hline${ }^{\mathrm{b}} \mathrm{T} 12$ muscle index, $\mathrm{cm}^{2} / \mathrm{m}^{2}$ & $11.6 \pm 3.0$ & $7.95 \pm 2.85$ & $<0.001$ & $11.0 \pm 2.4$ & $6.2 \pm 2.2$ & $<0.001$ \\
\hline Follow-up time, months & $38.8 \pm 21.0$ & $31.6 \pm 23.8$ & 0.087 & $39.7 \pm 21.6$ & $46.2 \pm 34.5$ & 0.603 \\
\hline GAP Index score & $3.3 \pm 1.3$ & $4.0 \pm 1.6$ & 0.012 & $2.7 \pm 1.3$ & $3.1 \pm 2.1$ & 0.610 \\
\hline 1-year survival, number, (\%) & $96(89.7 \%)$ & $28(77.8 \%)$ & 0.068 & $26(92.9 \%)$ & $7(77.8 \%)$ & 0.205 \\
\hline 2-year survival, number, (\%) & $86(80.4 \%)$ & $21(58.3 \%)$ & 0.008 & $25(89.3 \%)$ & $6(66.7 \%)$ & 0.109 \\
\hline
\end{tabular}

Data are presented as number of patients (\%) or mean \pm standard deviation

Abbreviations: $Q$ quartile, BMI Body Mass Index, FEV1 Forced Expiratory Volume, FVC Forced Vital Capacity, TLC Total Lung Capacity, DL $c 0$ diffusing capacity of carbon monoxide, CSA Cross Sectional Area, GAP gender, age, and physiologic variables 
corresponds to the lowest quartile of T4MI (men: T4MI $=32.53 \mathrm{~cm}^{2} / \mathrm{m}^{2}$; women: $\mathrm{T} 4 \mathrm{MI}=24.25 \mathrm{~cm}^{2} / \mathrm{m}^{2}$, respectively). In male patients, Forced Vital Capacity (FVC)\% predicted was lower and GAP index score was higher in the Sarcopenia group than in the normal group. Clinical characteristics, such as BMI, age, and smoking history did not differ between sarcopenia and normal groups. Respective 1-year survival rates of the Sarcopenia group and the normal group were 77.8 and $89.7 \%(P=0.068)$. Respective 2-year survival rates of the Sarcopenia group and the normal group were 58.3 and $80.4 \%(P=0.008)$. In female patients, although not statistically significant, the sarcopenia group showed a lower 2-year survival rate than that of the normal group $(89.3 \%$ vs $66.7 \%$, $P=0.109$ ).

Kaplan-Meier survival curves stratified by the sarcopenia and the normal group in male and female patients are shown in Fig. 3a. Male patients in the sarcopenia group exhibited a significantly lower survival rate $(P=0.035)$ than those of the normal group. There was no significant difference in survival between the sarcopenia and the normal group $(P=0.831)$ in Kaplan-Meier survival curves among female patients.

Furthermore, patients were stratified by the ESM $_{\mathrm{CSA}}$ divided by height square (T12MI) $(n=139)$; comparisons of clinical characteristics and survival between the lowest quartile of T12MI (Sarcopenia) (Q4) and the rest (normal) group $(\mathrm{Q} 1+2+3)$ are shown in Table 2. The cutoff value corresponds to the lowest quartile of T12MI (men: T12MI $=8.67 \mathrm{~cm}^{2} / \mathrm{m}^{2}$; women: $7.13 \mathrm{~cm}^{2} / \mathrm{m}^{2}$, respectively). In male patients, patients with sarcopenia exhibited lower survival although the difference was not statistically significant in men $(P=0.058)$. Respective 1-year survival rates of the sarcopenia group and normal groups were 82.8 and $89.4 \%(P=0.305)$. Respective 2-year survival rates of the sarcopenia and normal groups were 60.0 and $80.8 \%(P=0.013)$. In female patients, although not statistically significant, the sarcopenia group showed lower a 2-year survival rate than that of the normal group ( $92.3 \%$ vs $66.7 \%, P=0.058$ ).

Kaplan-Meier survival curves stratified by sarcopenia group and normal group in male and female patients are shown in Fig. 3b. Male patients in the sarcopenia group exhibited a lower survival rate $(P=0.058)$ than that of the normal group, although this was not statistically significant. There was no significant difference in survival rates between the normal and the sarcopenia groups $(P=0.660)$ in Kaplan-Meier survival curves among female patients.

\section{Cox proportional hazards analyses}

The relationships between all-cause mortality and clinical parameters, including T4MI and T12MI, were evaluated with Cox proportional hazards analysis (Table 3). Univariate analysis showed that lower BMI, lower FVC\% predicted value, lower $\mathrm{FEV}_{1} \%$ predicted value, lower $\mathrm{DL}_{\mathrm{CO}} \%$ predicted value, lower T4MI (HR, 0.965; 95\% CI, 0.937-0.993; $P=0.015$ ), lower T12MI (HR, 0.910; 95\% CI, 0.841-0.984; $P=0.019$ ), and a higher GAP index score were significantly correlated with all-cause mortality.
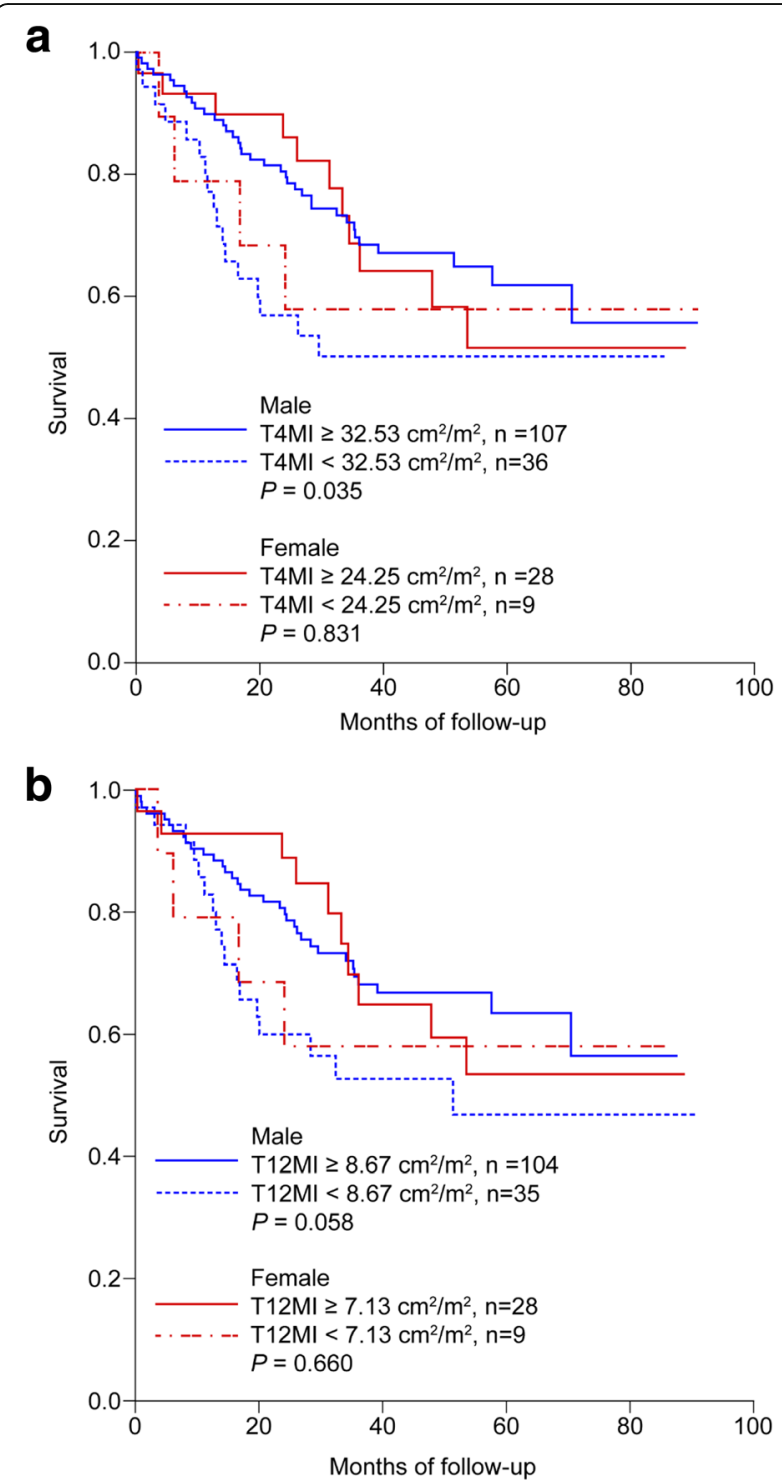

Fig. 3 a Kaplan-Meier survival curves stratified by the cross-sectional area of pectoralis, intercostalis, paraspinals, serratus, and latissimus muscles at the T4 level in male and female patients. The cutoff value corresponds to the lowest quantile of the cross-sectional area of muscle at the T4 level/height ${ }^{2}$ (T4 muscle index, T4MI) (Male: $\mathrm{T} 4 \mathrm{Ml}=32.53 \mathrm{~cm}^{2} / \mathrm{m}^{2}, n=108 / 35$ respectively / Female: $\mathrm{T} 4 \mathrm{Ml}=24.25$ $\mathrm{cm}^{2} / \mathrm{m}^{2}, n=28 / 9$ respectively). b Kaplan-Meier survival curves stratified by the cross-sectional area of the erector spinae muscles at the T12 level in male and female patients. The cutoff value corresponds to the lowest quantile of the cross-sectional area of erector spinae muscle/height ${ }^{2}$ (T12 muscle index, T12MI). (Male: $\mathrm{T} 12 \mathrm{Ml}=8.67 \mathrm{~cm}^{2} / \mathrm{m}^{2}, n=104 / 35$ respectively / Female: $\mathrm{T} 12 \mathrm{Ml}=7.13$ $\mathrm{cm} 2 / \mathrm{m} 2, n=28 / 9$ respectively) 
Table 3 Clinical factors associated with all-cause mortality in men and women patients (univariate analysis)

\begin{tabular}{|c|c|c|c|c|c|c|}
\hline \multirow[t]{2}{*}{ Variable } & \multicolumn{2}{|l|}{ Total $(n=180)$} & \multicolumn{2}{|l|}{ Men $(n=143)$} & \multicolumn{2}{|l|}{ Women $(n=37)$} \\
\hline & $\mathrm{HR}(95 \% \mathrm{Cl})$ & $P$ value & $\mathrm{HR}(95 \% \mathrm{Cl})$ & $P$ value & $\mathrm{HR}(95 \% \mathrm{Cl})$ & $P$ value \\
\hline Age, yr & $1.033(1.001-1.064)$ & 0.037 & $1.012(0.978-1.047)$ & 0.507 & $1.098(1.036-1.164)$ & 0.002 \\
\hline Sex, Female & $1.031(0.581-1.831)$ & 0.916 & & & & \\
\hline $\mathrm{BMI}, \mathrm{kg} / \mathrm{m}^{2}$ & $0.900(0.833-0.971)$ & 0.007 & $0.861(0.789-0.938)$ & 0.001 & $1.044(0.895-1.219)$ & 0.583 \\
\hline Smoking history, pack-years & $1.004(0.993-1.015)$ & 0.488 & $1.005(0.994-1.016)$ & 0.406 & $0.757(0.259-2.211)$ & 0.610 \\
\hline Diabetes, $\mathrm{n}$ & $1.495(0.922-2.425)$ & 0.103 & $1.275(0.731-2.222)$ & 0.392 & $2.521(0.907-7.012)$ & 0.076 \\
\hline Use of Statins or Sulfonylureas or Glinides, n & $0.962(0.588-1.576)$ & 0.879 & $0.944(0.538-1.655)$ & 0.840 & $0.964(0.341-2.725)$ & $0.945)$ \\
\hline FVC \% predicted & $0.958(0.944-0.973)$ & $<0.001$ & $0.961(0.945-0.977)$ & $<0.001$ & $0.943(0.907-0.982)$ & 0.004 \\
\hline FEV1, \% predicted & $0.973(0.960-0.986)$ & $<0.001$ & $0.975(0.961-0.989)$ & 0.001 & $0.964(0.932-0.996)$ & 0.030 \\
\hline DLCO \% predicted & $0.972(0.959-0.985)$ & $<0.001$ & $0.969(0.955-0.984)$ & $<0.001$ & $0.975(0.938-1.012)$ & 0.183 \\
\hline TLC, \% predicted & $0.970(0.950-0.990)$ & 0.004 & $0.970(0.950-0.990)$ & 0.004 & $0.944(0.882-1.009)$ & 0.091 \\
\hline${ }^{\mathrm{a}}$ 44 level muscle index, $\mathrm{cm}^{2} / \mathrm{m}^{2}$ & $0.965(0.937-0.993)$ & 0.015 & $0.958(0.926-0.991)$ & 0.013 & $0.972(0.904-1.044)$ & 0.433 \\
\hline${ }^{\mathrm{b}} \mathrm{T} 12$ level muscle index, $\mathrm{cm}^{2} / \mathrm{m}^{2}$ & $0.910(0.841-0.984)$ & 0.019 & $0.908(0.831-0.992)$ & 0.033 & $0.917(0.772-1.089)$ & 0.322 \\
\hline GAP Score & $1.356(1.137-1.619)$ & 0.001 & $1.366(1.112-1.678)$ & 0.003 & $1.403(0.977-2.014)$ & 0.067 \\
\hline
\end{tabular}

Data are presented as Hazard Ratios (95\% Confidence Intervals)

Abbreviations: BMI Body Mass Index, FEV1 Forced Expiratory Volume, FVC Forced Vital Capacity, $T L C$ Total Lung Capacity, DLCO diffusing capacity of carbon monoxide, CSA Cross Sectional Area, GAP gender, age, and physiologic variables

${ }^{a} \mathrm{~T} 4$ level muscle index $=$ CSA of pectoralis, intercostalis, paraspinals, serratus, and latissimus muscles at T4 level/height ${ }^{2}$

${ }^{\mathrm{b}} \mathrm{T} 12$ level muscle index $=\mathrm{CSA}$ of erector spinae muscle at T12 level/height ${ }^{2}$

Multivariate Cox proportional hazards analyses were performed to compare the contributions of these indices (Table 4). Stepwise Cox proportional hazards analysis demonstrated that lower BMI (HR, 0.885; 95\% CI, 0.806-0.972; $P=0.010$ ) and lower T4MI (HR, 0.955; 95\% CI, 0.913-0.998; $P=0.041$ ) were risk factors for all-cause mortality. Lower T12MI (HR, 0.980; 95\% CI, 0.856-1.121; $P=0.766)$ was not a significant risk factor for all-cause mortality after multivariate analysis. Higher GAP index score was a significant risk factor for all-cause mortality (HR, 1.450; 95\% CI, 1.169-1.760; $P=0.001$ ).

\section{Discussion}

To our knowledge, this study is the first to demonstrate that quantitatively analyzing muscles with chest CT can be useful in predicting the prognosis in patients with IPF. Our study showed that low T4MI is a risk factor for

Table 4 Clinical factors associated with all-cause mortality in the entire cohort (multivariate analysis)

\begin{tabular}{llll}
\hline Variables & HR & $95 \% \mathrm{Cl}$ & $\mathrm{P}$ value \\
\hline BMI, $\mathrm{kg} / \mathrm{m}^{2}$ & 0.885 & $0.806-0.972$ & 0.010 \\
Smoking history, pack-years & 0.993 & $0.977-1.009$ & 0.367 \\
${ }^{\mathrm{a}}$ T4 level muscle index, $\mathrm{cm}^{2} / \mathrm{m}^{2}$ & 0.955 & $0.913-0.998$ & 0.041 \\
bT12 level muscle index, $\mathrm{cm}^{2} / \mathrm{m}^{2}$ & 0.980 & $0.856-1.121$ & 0.766 \\
GAP Score & 1.450 & $1.169-1.760$ & 0.001
\end{tabular}

Data are presented as Hazard Ratios (95\% Confidence Intervals)

Abbreviations: BMI Body Mass Index, GAP gender, age, and physiologic variables

${ }^{\mathrm{a}}$ T4 level muscle index $=$ CSA of pectoralis, intercostalis, paraspinals, serratus, and latissimus muscles at $\mathrm{T} 4$ level/height ${ }^{2}$

${ }^{\mathrm{b}} \mathrm{T} 12$ level muscle index $=\mathrm{CSA}$ of erector spinae muscle at $\mathrm{T} 12$ level/height ${ }^{2}$ all-cause mortality in IPF patients, along with established and reported prognostic predictors.

There can be several reasons for the relationship between low T4MI with poor survival. First, muscles at the T4 level are involved with breathing; quantitative differences could result in altered performance, thus resulting in altered outcomes. Second, decreased lung function and symptoms of dyspnea could be reasons for reduced muscle mass. Reduced physical activity due to decreased lung function and dyspnea, is well-documented and this might result in reduced muscle mass $[19,20]$. However, it is unclear whether lower muscle mass led to increased disease severity, or whether increased disease severity led to lower muscle mass. Further studies investigating this mechanism are thus required.

Measurement of $\mathrm{T}_{\mathrm{CSA}}$ has several advantages, compared with parameters described in other reports pertaining to the skeletal muscles, [12] such as the psoas [14] and mid-thigh muscles [21]. Psoas muscle CSA may be affected by positions of upper extremities during scanning. Notably, other skeletal muscles require additional scans and X-ray exposure for analysis; however, a patient may not be able to undergo another evaluation of sarcopenia because of poor health. Without any additional radiation exposure, CSA analysis through existing chest CT scans provides an additional and important objective index of disease severity and future prognosis in patients with IPF.

In our study, Kaplan-Meier survival analysis for male patients with IPF who exhibited lower T12MI values 
demonstrated a significantly lower 2-year survival rate; however, it was not significant in multivariate Cox proportional hazards analysis. In the CT-based evaluation of sarcopenia, transverse skeletal muscle index at L3, which includes ESM, correlates well with whole-body composition measurements performed with dual-energy X-ray absorptiometry [22]. Similarly, there is possibility that measuring ESM at the level of T12 could have clinical significance if CSA of muscles involved in breathing are included in the analysis of CSA at the level of T12, considering the proximity of L3. More studies are needed to clarify the relationship between muscle CSA at the level of T12 and outcomes in IPF patients.

Many individual clinical variables have been shown to predict survival in IPF [23-25]. The effect of muscle mass on IPF prognosis was unknown. However, several studies $[6,14,15]$ suggested that thoracic muscle CSA is related to physical activity, quadriceps volume, and health-related quality of life in other lung diseases, such as lung transplantation, chronic obstructive lung disease, and non-small-cell lung cancer. Similarly, Izawa et al. suggested a relationship between respiratory muscle strength and sarcopenia in elderly cardiac patients [26]. Muscle mass involved in respiratory diseases may be also important for IPF patients; indeed, our results showed that skeletal muscle mass evaluated using chest CT can be a prognostic factor in IPF.

Our study has certain limitations. First, the study was retrospective study and the sample size was small, from a single center, and involved no replication cohort. Only Korean population were included in this study. This cut-off values cannot be used in other races or population considering that the cutoff for sarcopenia can differ among different races [27]. However, the validity of reported prognostic factors, such as the GAP score, was confirmed in this study population, which supports the present findings. In fact, the variables which were not statistically significant in the analysis of female patients could have been influenced by the small sample size. Second, a standard method for measuring CSA of the thoracic muscles has not yet been established. As reports regarding measurement of thoracic muscles are currently undergoing publication, we believe that a standard method for measuring CSA of thoracic muscles will soon be established. Third, the physical activity levels of all subjects were not directly evaluated. It is possible that there may be relationship to physical inactivity and lower muscle mass. We could not include data regarding physical function testing as these were not available at the time of analysis. However, based on other reports, $[4,5,13]$ we suspect that skeletal muscles of the chest may reflect both physical activity and physiological parameters. Further analysis is needed to verify these assumptions.

\section{Conclusions}

In conclusion, low $\mathrm{T} 4_{\mathrm{CSA}}$, normalized for stature, obtained from a single-slice axial chest $\mathrm{CT}$ image may be a strong risk factor for all-cause mortality in patients with IPF. Without additional radiation exposure, CSA analysis via existing chest $\mathrm{CT}$ scans provides an important index reflecting future prognosis in patients with IPF. This might aid in selection of an optimal treatment and enable early intervention to maintain muscle mass and improve prognosis. Close observation is needed in IPF patients with a lower skeletal muscle mass and early referral to lung transplantation program can be suggested in these patients if they fulfill the criteria for lung transplantation. Furthermore, referring to pulmonary rehabilitation can be beneficial in these patients. Additional studies are required to determine optimum reference values for predicting IPF-specific outcomes.

\section{Additional file}

\section{Additional file 1: Table S1. Comparisons between sarcopenia group (lower quartile of T12MI) (Q4) and the normal group (Q1 + Q2 + Q3) among men and women, respectively. (SAV $93 \mathrm{~kb}$ )}

\begin{abstract}
Abbreviations
BMI: Body mass index; COPD: Chronic obstructive pulmonary disease; CSA: Cross-sectional area; CT: Computed tomography; DLCO: Diffusing capacity of carbon monoxide; ESM: Erector spinae muscle; ESMCSA: Crosssectional area measured at erector spinae muscle; FEV1: Forced expiratory volume; FVC: Forced vital capacity; GAP index: Gender-Age-Physiology Index; IPF: Idiopathic pulmonary fibrosis; MI: Muscle index; SD: Standard deviation; T4CSA: Cross-sectional area measured at T4; TLC: Total lung capacity
\end{abstract}

\section{Acknowledgements}

The authors are grateful to the Radiologic department of Severance hospital.

Funding

This research did not receive any specific grant from funding agencies in the public, commercial, or not-for-profit sectors.

Availability of data and materials

All data generated or analysed during this study are included in this published article as 'Additional file 1'.

\section{Authors' contributions}

SY. K. and SW. M. conceived and designed the study; SW. M., SH. L., JS. C., and KS. J. acquired the clinical data; SW. M. and SY. K. conducted the statistical analysis; and J. J., YS. K., MS. P., YA. K. and JY. J. were involved in radiologic support. SY. K. and SW. M. had full access to all the data in the study and take responsibility for the integrity of the data and accuracy of the analysis. All authors designed the study, interpreted the data, critically revised the manuscript for important intellectual content, and approved the submitted version.

\section{Ethics approval and consent to participate}

This research protocol was approved by the Institutional Review Board of Severance Hospital, South Korea (IRB No.4-2018-0454). The requirement to obtain informed patient consent was waived.

Consent for publication

Not applicable.

Competing interests

The authors declare that they have no competing interest. 


\section{Publisher's Note}

Springer Nature remains neutral with regard to jurisdictional claims in published maps and institutional affiliations.

Received: 1 November 2018 Accepted: 6 February 2019

Published online: 15 February 2019

\section{References}

1. Muscaritoli M, Anker SD, Argiles J, Aversa Z, Bauer JM, Biolo G, Boirie Y, Bosaeus I, Cederholm T, Costelli P, et al. Consensus definition of sarcopenia, cachexia and pre-cachexia: joint document elaborated by special interest groups (SIG) "cachexia-anorexia in chronic wasting diseases" and "nutrition in geriatrics". Clin Nutr (Edinburgh, Scotland). 2010;29(2):154-9.

2. Okumura S, Kaido T, Hamaguchi Y, Kobayashi A, Shirai H, Fujimoto Y, lida T, Yagi S, Taura K, Hatano E, et al. Impact of skeletal muscle mass, muscle quality, and visceral adiposity on outcomes following resection of intrahepatic cholangiocarcinoma. Ann Surg Oncol. 2017;24(4):1037-45.

3. Deluche E, Leobon S, Desport JC, Venat-Bouvet L, Usseglio J, TubianaMathieu N. Impact of body composition on outcome in patients with early breast cancer. Support Care Cancer. 2018;26(3):861-68. https://doi.org/10. 1007/s00520-017-3902-6. Epub 2017 Sep 25.

4. Kim EY, Kim YS, Park I, Ahn HK, Cho EK, Jeong YM. Prognostic significance of CT-determined sarcopenia in patients with small-cell lung Cancer. J Thorac Oncol. 2015:10(12):1795-9.

5. Kim EY, Kim YS, Park I, Ahn HK, Cho EK, Jeong YM, Kim JH. Evaluation of sarcopenia in small-cell lung cancer patients by routine chest $C T$. Support Care Cancer. 2016;24(11):4721-6.

6. Tsukioka T, Nishiyama N, Izumi N, Mizuguchi S, Komatsu H, Okada S, Toda M, Hara K, Ito R, Shibata T. Sarcopenia is a novel poor prognostic factor in male patients with pathological stage I non-small cell lung cancer. Jpn J Clin Oncol. 2017:47(4):363-8.

7. Zuckerman J, Ades M, Mullie L, Trnkus A, Morin JF, Langlois Y, Ma F, Levental $\mathrm{M}$, Morais JA, Afilalo J. Psoas muscle area and length of stay in older adults undergoing cardiac operations. Ann Thorac Surg. 2017;103(5):1498-504.

8. Fujimoto H, Kobayashi T, Azuma A. Idiopathic pulmonary fibrosis: treatment and prognosis. Clin Med Insights Circ Respir Pulm Med. 2015;9(Suppl 1): 179-85.

9. Heymsfield SB, Gonzalez MC, Lu J, Jia G, Zheng J. Skeletal muscle mass and quality: evolution of modern measurement concepts in the context of sarcopenia. Proc Nutr Soc. 2015;74(4):355-66

10. Jones KI, Doleman B, Scott S, Lund JN, Williams JP. Simple psoas cross-sectional area measurement is a quick and easy method to assess sarcopenia and predicts major surgical complications. Color Dis. 2015;17(1):020-6.

11. Rangel EL, Rios-Diaz AJ, Uyeda JW, Castillo-Angeles M, Cooper Z, Olufajo OA, Salim A, Sodickson AD. Sarcopenia increases risk of long-term mortality in elderly patients undergoing emergency abdominal surgery. J Trauma Acute Care Surg. 2017;83(6):1179-1186. https://doi.org/10.1097/TA.0000000000001657.

12. Fuseya Y, Hasegawa K, Uemasu K, Sato A, Oguma T, Hirai T, Mishima M, Muro S. Quantitative assessment of erector spinae muscles in patients with chronic obstructive pulmonary disease. Novel chest computed tomographyderived index for prognosis. Ann Am Thorac Soc. 2016;13(3):334-41. https:// doi.org/10.1513/AnnalsATs.201507-4460C.

13. Mathur S, Rodrigues N, Mendes P, Rozenberg D, Singer LG. Computed tomography-derived thoracic muscle size as an Indicator of sarcopenia in people with advanced lung disease. Cardiopulm Phys Ther J. 2017;28(3):99-105.

14. McDonald ML, Diaz AA, Ross JC, San Jose Estepar R, Zhou L, Regan EA, Eckbo E, Muralidhar N, Come CE, Cho MH, et al. Quantitative computed tomography measures of pectoralis muscle area and disease severity in chronic obstructive pulmonary disease. A cross-sectional study. Ann Am Thorac Soc. 2014;11(3):326-34.

15. Rozenberg D, Mathur S, Herridge M, Goldstein R, Schmidt H, Chowdhury NA, Mendes $P$, Singer $L G$. Thoracic muscle cross-sectional area is associated with hospital length of stay post lung transplantation: a retrospective cohort study. Transplant Int. 2017:30(7):713-24.

16. Raghu G, Collard HR, Egan JJ, Martinez FJ, Behr J, Brown KK, Colby TV, Cordie JF, Flaherty KR, Lasky JA, et al. An official ATS/ERS/JRS/ALAT statement: idiopathic pulmonary fibrosis: evidence-based guidelines for diagnosis and management. Am J Respir Crit Care Med. 2011;183(6):788-824.

17. Ley $B$, Ryerson $C J$, Vittinghoff $E$, et al. A multidimensional index and staging system for idiopathic pulmonary fibrosis. Ann Intern Med. 2012; 156(10):684-91.
18. Campins L, Camps M, Riera A, Pleguezuelos E, Yebenes JC, Serra-Prat M. Oral drugs related with muscle wasting and sarcopenia. A review. Pharmacology. 2017;99(1-2):1-8.

19. Di Marco F, Terraneo S, Roggi MA, Repossi AC, Pellegrino GM, Veronelli A, Santus P, Pontiroli AE, Centanni S. Physical activity impairment in depressed COPD subjects. Respir Care. 2014;59(5):726-34.

20. Vaz Fragoso CA, Beavers DP, Hankinson JL, Flynn G, Berra K, Kritchevsky SB, Liu CK, McDermott MM, Manini TM, Rejeski WJ, et al. Respiratory impairment and dyspnea and their associations with physical inactivity and mobility in sedentary community-dwelling older persons. J Am Geriatr Soc. 2014;62(4):622-8

21. Marquis K, Debigare R, Lacasse $Y$, LeBlanc $P$, Jobin J, Carrier G, Maltais $F$. Midthigh muscle cross-sectional area is a better predictor of mortality than body mass index in patients with chronic obstructive pulmonary disease. Am J Respir Crit Care Med. 2002;166(6):809-13.

22. Shen W, Punyanitya M, Wang Z, Gallagher D, St-Onge MP, Albu J, Heymsfield SB, Heshka S. Total body skeletal muscle and adipose tissue volumes: estimation from a single abdominal cross-sectional image. J Applied Physiol (Bethesda, Md : 1985). 2004;97(6):2333-8.

23. Collard HR, King TE Jr, Bartelson BB, Vourlekis JS, Schwarz Ml, Brown KK. Changes in clinical and physiologic variables predict survival in idiopathic pulmonary fibrosis. Am J Respir Crit Care Med. 2003;168(5):538-42.

24. Ley B, Collard HR, King TE Jr. Clinical course and prediction of survival in idiopathic pulmonary fibrosis. Am J Respir Crit Care Med. 2011;183(4):431-40.

25. King TE Jr, Tooze JA, Schwarz MI, Brown KR, Cherniack RM. Predicting survival in idiopathic pulmonary fibrosis: scoring system and survival model. Am J Respir Crit Care Med. 2001;164(7):1171-81.

26. El-Gamal H, Khayat A, Shikora S, Unterborn JN. Relationship of dyspnea to respiratory drive and pulmonary function tests in obese patients before and after weight loss. Chest. 2005;128(6):3870-4.

27. Kruger HS, Micklesfield LK, Wright HH, Havemann-Nel L, Goedecke JH. Ethnic-specific cut-points for sarcopenia: evidence from black south African women. Eur J Clin Nutr. 2015:69(7):843-9.

\section{Ready to submit your research? Choose BMC and benefit from:}

- fast, convenient online submission

- thorough peer review by experienced researchers in your field

- rapid publication on acceptance

- support for research data, including large and complex data types

- gold Open Access which fosters wider collaboration and increased citations

- maximum visibility for your research: over $100 \mathrm{M}$ website views per year

At $\mathrm{BMC}$, research is always in progress.

Learn more biomedcentral.com/submission 